\title{
Elektrikli Isıtıcı Elemanları Üretiminde Hedef Programlama Yaklaşımı ile Tedarikçi Seçimi
}

\author{
Evren Can ÖZCAN $^{1 *}$, Bahar ÖZYÖRÜK ${ }^{2}$ \\ ${ }^{1}$ Bakım Yönetim Sistemi Müdürlüğü, Elektrik Üretim A.Ş. Genel Müdürlüğü, Ankara, Türkiye \\ ${ }^{2}$ Endüstri Mühendisliği Bölümü, Gazi Üniversitesi, Ankara, Türkiye \\ enmcan@gmail.com, bahar@gazi.edu.tr \\ (Geliș/Received:18.01.2017; Kabul/Accepted:01.06.2017) \\ DOI: $10.17671 /$ gazibtd. 331039
}

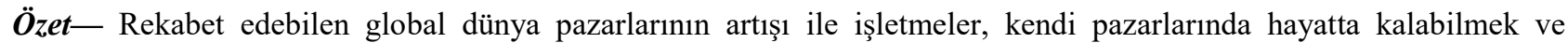
rekabet edebilme yeteneklerini sürdürmek için üretim ve malzeme maliyetlerini düşürmenin yollarını bulmak adına çok büyük bir baskının altına girmişlerdir. Bu bağlamda, maliyetlerin azaltılmasında alıcı için nitelikli tedarikçinin bir anahtar eleman ve iyi bir kaynak olması nedeniyle potansiyel tedarikçilerin birden fazla amaç dikkate alınarak değerlendirilmesi ve seçimi, tedarik zinciri yönetiminin önemli bir bileşeni konumuna gelmiştir. Bu kapsamda bu çalışmada, tedarikçi seçimi için çok amaçlı optimizasyon yöntemlerinden birisi olan hedef programlama yaklaşımı kullanılmıştır. Uygulama kapsamında, elektrikli 1sıtıcı elemanları üreten bir firmadaki 6 ürün grubu için $\mathrm{ABC}$ sınıflandırması yapılmış ve en önemli ürün grubu olarak firın rezistansı belirlenmiştir. Ardından bu ürün grubunun kritik 3 parçası için 8 tedarikçi, firma yöneticilerinin belirlemiş olduğu 3 hedefi birlikte ele alan bir deterministik hedef programlama modeli ile değerlendirilmiştir. Bu modelin çözümü sonucunda firma amaçlarına en uygun tedarikçi kombinasyonu belirlenmiştir.
\end{abstract}

Anahtar Kelimeler — tedarikçi seçimi, hedef programlama, ABC sınıflandırması, elektrikli ısıtıcı elemanları üretimi

\section{Supplier Selection with Goal Programming Approach in Electrical Heating Elements Production}

\begin{abstract}
With increasingly competitive global world markets, companies have been under intense pressure to find ways to reduce production and material costs to survive and sustain their competitive capability in their respective markets. In this context, evaluation and selection of the potential suppliers by considering more than one goal has become an important component of supply chain management since a qualified supplier is a key element and a good resource for a buyer in reducing such costs. Within this scope in this study, a goal programming approach which is one of the multi-objective optimization methods is used for the supplier selection. Within the application, ABC classification is performed for six product groups which are produced in an electrical heating elements firm and oven resistance has been determined as the most important product group. After that, eight suppliers are evaluated for this product's three critical elements with deterministic goal programming model which handled three goals determined by the firm managers as together. After the solution of this problem, the most suitable supplier combination to the firm's objectives is obtained.
\end{abstract}

Keywords - supplier selection, goal programming, ABC classification, electrical heating elements production

\section{GİRİS (INTRODUCTION)}

Günümüzün rekabetçi pazar koşullarında işletmeler, yüksek kâr ve müşteri memnuniyeti, kalite düzeyi yüksek ürünler ve kısa teslim süresi gibi firsatlar için organizasyonel yapılarını düzenleme gereği içindedir. İşletmelerin bu hedeflerine ulaşabilmeleri için akademisyenlerin ve pazardaki lider uygulamaciların uzlaştıkları nokta, işletmelerin bir tedarik zinciri içerisinde ve bu zincirin toplam performansını artıracak doğrultuda çalışma zorunluluklarının kesinliği konusundadır. Tedarik zincirindeki gelişmeler ve globalleşmenin etkileri de düşünüldüğünde, işletmelerin dış kaynak ve hizmet kullanım oranlarının artışı göze çarpmaktadır. $\mathrm{Bu}$ nedenlerden dolayı satın alma fonksiyonu ve bu fonksiyon dahilindeki kararlar her 
geçen gün daha da önem kazanmaktadır. Bu kararların en önemlilerinden birisi de şüphesiz ki tedarikçi seçimidir [1].

Tedarikçi seçimi, tedarik zinciri yönetimindeki karar verme proseslerinde anahtar faktörlerdendir. Uygun tedarikçilerin seçimi ile satın alma maliyetleri azaltılmakta ve işletmelerin rekabet güçleri etkin bir şekilde yükselebilmektedir [2,3]. Bununla birlikte firmalar, bulundukları sektörlerde maruz kaldıkları riskleri azaltmak için çekirdek yeterliliklerini inşa ederek uygun tedarikçileri belirlemek zorundadır [4]. Uygun tedarikçilerin belirlenmesinin üzerine seçilen tedarikçiler ile yapılacak uzun dönemli anlaşmalar ise, firmaların tedarik zincirlerinin potansiyel rakiplerine karşı son derece güçlü bir kalkan oluşturmasına olanak sağlamaktadır [5]. Bunun yanı sıra firmalar, toplam maliyetlerini (seçim, satın alma, taşıma ve depolama maliyetleri) azaltmak ve tedarik zinciri performanslarını mümkün olan en üst seviyeye çıkarmak için, spesifik olarak seçtikleri tedarikçiler arasında sipariş miktarını dağıtma yoluna gidebilirler [6].

Tüm bu açıklamalardan hareketle özet olarak, tedarikçi seçiminin tedarik zinciri yönetiminin kritik ilk aşaması olduğu ve bundan sonraki tüm aşamaları etkilediği yorumu yapılabilir. Başka bir deyişle, tedarikçilerin etkin yönetimi oluşturulan tedarik zincirinde rekabet gücünün artırılmasında kalıcı etkiler meydana getirilebilir [7].

$\mathrm{Bu}$ bağlamda bu çalışma kapsamında, malzeme kalitesinin düşüklüğü temel nedeniyle fire oranları yüksek olan ve buna bağlı olarak kapasitesini etkin kullanamayan, aynı zamanda malzeme tedariki için tahsis ettiği parasal değeri kontrol altında tutmayı amaçlayan bir elektrikli 1sıtıcı elemanları üreticisinde, söz konusu sorunların tedarikçi yönetimindeki aksaklıklardan kaynaklı olduğu tespit edilmiş ve bu problemlere çözüm olacak kapsamlı bir analiz yapılmıştır. Bu analizin ilk aşamasında, firmanın ürettiği ürünler, kullanım yeri, çalışma gerilimi, boyu ve ürettiği güce göre gruplandırılmış ve bu gruplar, ürünlere olan yıllık ortalama talep ve birim satış fiyatları üzerinden $\mathrm{ABC}$ analizi ile değerlendirilerek firma için en önemli ürün grubunun firın rezistansları olduğu tespit edilmiştir. Ardından, fırın rezistanslarının üretim süreci incelenerek seçilen ürünün (en çok işlem hacmine sahip rezistans) standart zamanı hesaplanmış ve bu ürün grubunun üretiminde kullanılan 3 kritik malzeme için potansiyel 8 tedarikçinin firma yöneticileri ile belirlenen 3 hedefe göre en uygun kombinasyonunun bulunması için, amaç fonksiyonunun doğrusal, karar değişkenlerinin tamsayılı ve katsayıların deterministik olduğu bir hedef programlama modeli önerilmiştir. Önerilen modelin, belirlenen 3 amacın öncelik sıraları değiştirilerek elde edilen 18 kombinasyona ait çözümü neticesinde, en uygun tedarikçi kombinasyonu ile bu tedarikçilerden temin edilmesi gereken malzeme miktarları elde edilmiş ve söz konusu sonuçların uygulanması sonucunda firmanın kapasite kullanımı ve fire oranları ile ilgili kazanımları sunulmuştur.

\section{LITERATÜR ARAŞTIRMASI (LITERATURE REVIEW)}

Tedarikçi seçimi, bir tedarik zincirinin etkin ve başarılı bir şekilde işletilmesi için önemi yüksek bir gereklilik prosesi olması sebebiyle birçok araştırmacı tarafından ele alınmıştır. Buna bağlı olarak, literatürde sıklıkla karşılan bu çalışmalar üzerine yapılmış birçok literatür araştırması da mevcuttur. Bunlardan ilki Weber vd. [8] tarafından 1991 yılında gerçekleştirilmiş olup, çalışmada tedarikçi seçim kriterleri ve metotlarına odaklanılmıştır. Sonraki yıllarda DeBoer vd. [9], Aissaoui vd. [1], Ho vd. [10], Lee vd. [11], Genovese vd. [12], Igarashi vd. [13], Chai vd. [14] ve Wetstein vd. [15] tarafindan yapılan literatür araştırmalarında inceleme odakları, tedarikçi seçimini destekleyen metotlar [9], tedarikçi seçimi ve sipariş parti büyüklüğü modelleri [1], tedarikçi değerlendirme ve seçimi için çok kriterli karar verme yaklaşımları [10, 14], yeşil tedarikçi seçimi için anahtar kriterler, gereklilikler ve modeller [11-13] olarak belirlenmiştir. Wetstein vd. [15] ise, yukarıdaki amaçların tamamını ele alarak sistematik bir yaklaşımla literatüre katkı sağlamıştır.

Tedarikçi seçimi için literatürde yapılan çalışmalarda birçok yöntem kullanılmıştır. Bu yöntemler arasında çok kriterli karar verme teknikleri, veri zarflama analizi, doğrusal ve doğrusal olmayan programlama, çok amaçlı programlama, hedef programlama, stokastik programlama, yapay zeka teknikleri ve bulanık yaklaşımlar sayılabilir [14]. Bu çalışma kapsamında, tedarikçi seçim kararı önerilen hedef programlama modeli ile verildiği için, çok geniş olan tedarikçi seçim literatüründen sadece hedef programlama yaklaşımı kullanılan çalışmalardan bazıları aşağıda sunulmuştur.

Kumar vd. çalışmalarında, bulanık karışık tamsayılı hedef programlama yaklaşımını kullanmışlar ve net maliyeti, red oranlarını ve gecikmeleri minimize etme amaçlarını belirlemişlerdir [16]. Araz vd., tedarikçi seçim problemini bir tekstil firmasında ele almışlar ve problemin çözümünde bulanık hedef programlama yaklaşımını kullanmışlardır. Firmanın var olan tedarikçileri PROMETHEE kullanımı ile değerlendirilmiş ve önerilen model ile firma amaçlarına en uygun tedarikçilerin seçimi yapılarak, eş zamanlı olarak sipariş bu tedarikçilere dağıtılmıştır. Modelin kullanımının öncesi ve sonrasındaki sonuçlar karşılaştırılmış ve bu bilimsel yaklaşımın tedarikçi yönetim sistemi açısından firmaya çok önemli faydalar sağladığı sonucuna ulaşılmıştır [17]. Özder ve Eren [18], 
otomotiv sektöründe faaliyet gösteren bir firmanın tedarikçilerini ANP-hedef programlama yaklaşımı ile belirlemişlerdir. Özder vd. [19] ise, yine otomotiv sektörü için kombine TOPSIS-hedef programlama yaklaşımı ile tedarikçi seçim literatürüne katkı sağlamışlardır. Kull ve Talluri [20], her bir alternatif tedarikçinin risk indeksini AHP ile hesapladıkları bir değerlendirme yaklaşımı sunmuşlardır. $\mathrm{Bu}$ indeksler daha sonra, ürün hayat çevriminde uygulanan hedef programlama modelinde kullanılmıştır. Tsai ve Hung [21], bulanık hedef programlama yaklaşımı ile tedarikçi seçim problemini çözmüşler, Demirtaş ve Üstün [22] ise, tedarikçi seçimi için çok periyotlu planlama dönemini dikkate alarak önerdikleri ANP-hedef programlama hibrit modelini kullanmışlardır. Chen [23], hedef programlamanın önemli bir bileşen olduğu birçok matematiksel programlama tekniklerini entegre ettiği modeli literatüre kazandırmıştır. Literatürdeki çalışmalarda kullanılan hibrit yöntemler, sıklıkla çok kriterli karar verme yaklaşımları ile hedef programlama entegrasyonu şeklinde yapılmışsa da, Sadeghieh vd. [24]'nin çalışmasında olduğu gibi genetik algoritma gibi yapay zeka yaklaşımları da hedef programlama ile birlikte kullanılmıştır.

\section{HEDEF PROGRAMLAMA (GOAL PROGRAMMING)}

İnsanlar yaşamları boyunca, belirledikleri amaçlar doğrultusunda ve birbirleri ile çelişen ya da ilişkili kriterlere bağlı olarak kararlar almak durumundadır. Çalışmanın da konusunu teşkil eden ve rekabet gücünün artırılması, kâr maksimizasyonu, maliyet minimizasyonu, ürün kalite düzeyinin ve müşteri memnuniyetinin artırılması gibi üst ölçekteki hedeflere ulaşılmasında firmalara önemli katkılar sağlayan tedarikçi seçimi gibi kritik kararların verilmesi sürecinde ise, analitik yaklaşımların kullanılması kararların etkinliği açısından büyük önem arz etmektedir. Bu bağlamda, çok amaçlı doğrusal programlamanın genelleştirilmiş bir hali ya da uzantısı olarak ele alınabilecek [14] hedef programlama, bu analitik yaklaşımlar bütününden birisi olan yöneylem araştırmasının bir alt dalı olarak tedarikçi seçimi de dahil olmak üzere etkin karar vermede sıklıkla kullanılmaktadır.

Hedef programlamada mümkün olduğu kadar bütün hedeflere en iyi şekilde ulaşılması istenir. $\mathrm{Bu}$ nedenle, belirlenen her amaç tek tek ele alınıp, amaçlara ulaşılamama ölçüsüyle ilgilenilir ve amaçlar arasındaki sapmaların, kısıtlar kümesine uygun olarak minimize edilmesine çalışılır. Özetle hedef programlamanın genel amacı, değerleri kesin olarak belirlenen birden fazla amacın, hedef değerlerinden sapmalarını minimize etmektir.

Hedef programlamanın matematiksel gösterimi aşağıda verilmiştir [25].
Minimize $Z=\sum_{i=1}^{k}\left(d_{i}^{-}+d_{i}^{+}\right)$

$\sum_{j=1}^{n} a_{i j} x_{j}+d_{i}^{-}-d_{i}^{+}=b_{i}$

$x_{j}, d_{i}^{-}, d_{i}^{+} \geq 0$

$i=1 \ldots k \quad j=1 \ldots n$

Notasyonlar

$x_{j}: j$. Karar değişkeni

$a_{i j}: i$. hedefin $j$. karar değişkeni katsayısı

$b_{i}: i$. hedef için ulaşılmak istenen değer

$d_{i}^{+}: i$. hedefin pozitif sapma değişkeni

$d_{i}^{-}: i$. hedefin negatif sapma değişkeni

\section{UYGULAMA (CASE STUDY)}

Türkiye'de 50 yılı aşkın süredir yurt içi ve yurt dışı pazarda faaliyet gösteren, ana üretim konusu beyaz eşya sektörü ve evsel elektrikli cihazlar için metal ve bakır boru k1lıflı elektrikli 1sıtıc1 elemanları olan bir firmada önemli ekonomik kaynakların aktarılmasına rağmen malzeme kalitesine bağlı olarak fire oranlarının yükseldiği, kapasite kullanım oranının düştüğü ve bunlara bağlı olarak sektörel itibarın ve rekabet gücünün azaldığ1 tespit edilmiş, bu sorunların çözümünün başlangıç aşamasının tedarikçi yönetimi olmasından hareketle kritik malzeme kalemleri için en uygun tedarikçi kombinasyonunun belirlenmesine karar verilmiştir. Bu kapsamda ilk olarak, firma için en önemli ürün grubu firın rezistansı olarak $\mathrm{ABC}$ analizi ile tespit edilmiş ve bu ürün grubu içinde en yüksek işlem hacmine sahip olan 1sıtıcı için standart zaman hesaplanmıştır. Ardından firma yöneticileri ile tespit edilen fire oranlarının minimizasyonu, kapasite kullanım oranının maksimizasyonu ve stok için ayrılan parasal miktarın minimizasyonu hedeflerinin eş zamanlı olarak dikkate alındığı bir hedef programlama modeli önerilerek, kritik 3 malzeme kalemi için potansiyel 8 tedarikçi arasından en uygun kombinasyon ve bunlara verilmesi gereken sipariş miktarları belirlenmiştir. $\mathrm{Bu}$ tedarikçi kombinasyonuna bağlı olarak yapılan alımlar neticesinde, firmanın fire oranlarındaki ve kapasite kullanım oranındaki değişim sonuç bölümünde vurgulanmıştır.

\section{1. Ürün Grubunun Belirlenmesi (Determination of the Product Group)}

Firmanın ürettiği ürünler, ürünün kullanılacağı yer (tip), çalışma gerilimi, boyu ve ürettiği güce göre çeşitlenmektedir. Bu nedenle, çok fazla sayıda ürün çeşidi söz konusudur. Ancak, ana başlıklar halinde firmada üretilen ürünler tipleri baz alınarak 6 grup olarak ele alınabilmektedir. Ürün grupları, ürünlere olan yıllık ortalama talep ve birim satış fiyatları Tablo 1'de verilmiştir. 
Tablo 1. Ürün gruplarının yıllık ortalama talep miktarları ve satış fiyatları

(Average annual demands and sale prices)

\begin{tabular}{|l|c|c|}
\hline \multicolumn{1}{|c|}{ Ürün Grubu } & $\begin{array}{c}\text { Yıllık } \\
\text { Ortalama } \\
\text { Talep (Adet) }\end{array}$ & $\begin{array}{c}\text { Birim Fiyat } \\
(\boldsymbol{\epsilon})\end{array}$ \\
\hline Fırın rezistansı (FR) & 23.880 & 5,1 \\
\hline Barbekü rezistansı (BR) & 7.463 & 1,1 \\
\hline Tost rezistansı (TR) & 14.179 & 0,9 \\
\hline Endüstriyel 1sıtıcılar (EI) & 9.701 & 1,2 \\
\hline Şofben rezistansı (SSR) & 13.433 & 1,0 \\
\hline Serpantinli 1sitıcılar (SR) & 5.970 & 1,3 \\
\hline
\end{tabular}

Tablo 1'de belirtilen ürün gruplarının üretiminde kullanılan önemli malzeme kalemleri (sac, tel ve kum) aynıdır. $\mathrm{Bu}$ nedenle, bir ürün grubunda sağlanacak iyileşme, tüm ürün gruplarına yansıyacaktır. Önerilen model, kritik 3 malzeme kalemi için en uygun tedarikçi kombinasyonunu belirlemesinin yanı sira, her bir tedarikçiden karşılanması gereken malzeme miktarını da verdiği ve belirlenen amaçlardan bir tanesinin kapasite kullanım oranı maksimizasyonu olmasından dolayı, 6 ürün grubu arasından bir tanesinin belirlenerek zaman etüdü yapılması gerekmektedir. $\mathrm{Bu}$ bağlamda, yıllık ortalama talep miktarları ve satış fiyatları üzerinden firma için en önemli ürün grubunun belirlenmesi için ABC analizi [26] kullanılarak "A" sınıfına düşen ürün grubu tespit edilmiştir.

ABC analizinde dikkate alınan sınıf aralıkları Şekil 1'de gösterilmiştir.

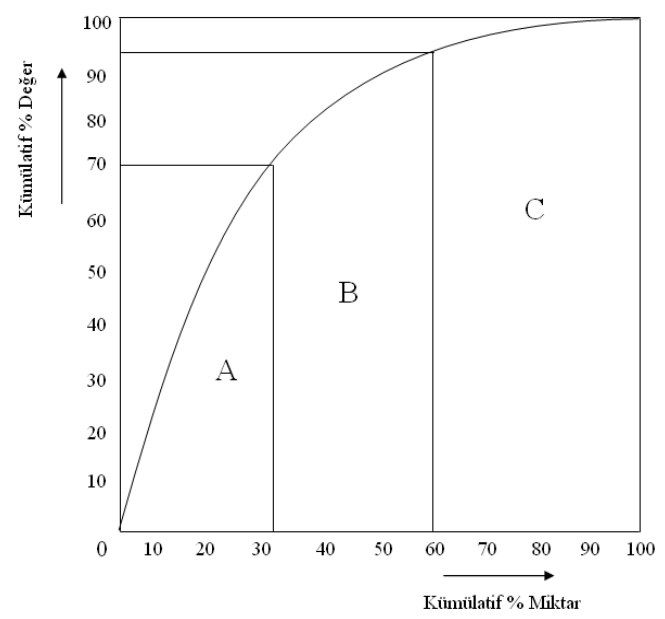

Şekil 1. ABC analizinde dikkate alınan sınıf aralıkları (Class intervals considering in $A B C$ analysis)

ABC analizinde ilk olarak, ürünlere olan yıllık ortalama talep miktarları ile birim ürün fiyatları çarpılarak yıllık talebin parasal değerleri bulunmuştur. Bulunan bu değerler büyükten küçüğe doğru siralandıktan sonra, kümülatif tüketimin parasal değerleri ve kümülatif miktarlar tespit edilmiştir. Eldeki bu verilere göre son aşamada, parasal değer ve miktar açısından kümülatif yüzdeler normalizasyonla hesaplanarak her sınıfa düşen ürün grupları belirlenmiştir. $\mathrm{ABC}$ analizine ait sonuçlar Tablo 2'de gösterilmiştir.

Tablo 2. ABC analizi sonuçları

(Results of $A B C$ analysis)

\begin{tabular}{|l|c|c|c|c|c|}
\hline $\begin{array}{c}\text { Ürün } \\
\text { Grubu }\end{array}$ & $\begin{array}{c}\text { Yüllı } \\
\text { Tüketim } \\
(\boldsymbol{\epsilon})\end{array}$ & $\begin{array}{c}\text { Küm. } \\
\text { Tüketim } \\
(\boldsymbol{€})\end{array}$ & $\begin{array}{c}\text { Küm. } \\
\text { Yüzde } \\
(\boldsymbol{€})\end{array}$ & $\begin{array}{c}\text { Küm. } \\
\text { Tüketim } \\
(\text { Adet) }\end{array}$ & $\begin{array}{c}\text { Küm. } \\
\text { Yüzde } \\
\text { (Adet) }\end{array}$ \\
\hline FR & 121.788 & 121.788 & $\mathbf{6 9 , 3}$ & 23.880 & $\mathbf{3 2 , 0}$ \\
\hline ŞR & 14.179 & 135.967 & 77,4 & 38.059 & 51,0 \\
\hline TR & 12.089 & 148.056 & 84,3 & 51.491 & 69,0 \\
\hline EI & 11.642 & 159.698 & 90,9 & 61.193 & 82,0 \\
\hline BR & 8.209 & 167.906 & 95,6 & 68.655 & 92,0 \\
\hline SR & 7.761 & 175.667 & 100,0 & 74.625 & 100,0 \\
\hline
\end{tabular}

Tablo 2'deki sonuçlar ve Şekil 1'deki sınıf aralıklarına göre, firın rezistansı "A" sinıfı ürün grubu olarak belirlenmiştir.

Fırın rezistansları, kullanılan malzeme ve üretimde geçirdiği işlemler açısından tamamen benzerdir. Daha öncede belirtildiği gibi ürünün çalışma gerilimi, boyu ve ürettiği güçteki farklılıklara göre fırın rezistansı çeşitleri oluşmaktadır. Firmadan alınan bilgilere göre en çok işlem hacmine sahip firın rezistansı, $230 \mathrm{~V}$ gerilim altında $900 \mathrm{~W}$ güç üreten ve $1.520 \mathrm{~mm}$ boru boyuna sahip 1sitıcıdır. Bu rezistans için ürün ağacı Tablo 3'deki gibidir.

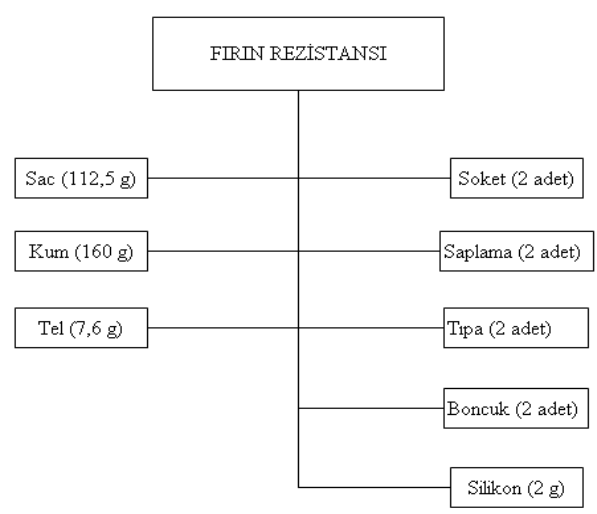

Şekil 3. Seçilen firın rezistansına ait ürün ağacı

(Bill of material of the selected oven resistance)

4.2. Seçilen Ürün için Zaman Etüdü (Time Study for the Selected Product)

Seçilen firın rezistansı için standart zamanın bulunması amacıyla zaman etüdü yapılmıştır. Bu kapsamda, üretim 7 istasyona bölünmüş (boru imalat, tel sarma, dolum, hadde-tav, büküm, silikon ve montaj) ve her istasyondaki 
akış dilimleri belirlenmiştir. Akış dilimleri 15 çevrimde ayrı ayrı gözlemlenmiş ve kronometraj ölçüm yapılmıştır. Gecikme ve bekleme zamanları da dikkate alınarak yapılan zaman etüdü neticesinde seçilen firın rezistansina ait standart zaman 1,91 dakika olarak hesaplanmıştır. Önerilen modelde sac, kum ve telden oluşan kritik malzeme gruplarına ilişkin parametreler yer aldığı için, hesaplanan standart zamanın söz konusu malzemelerin işlendiği istasyonlar için değerlerine ihtiyaç duyulmaktadır. Bu kapsamda, söz konusu değerler ve bunların hesaplanmasında izlenen yol aşağıda maddeler halinde verilmiştir:

- Boru imalat bölümünde 3 farklı işlem gerçekleştirilmektedir. Bunlardan doğrultma işlemi için verilen süre 28 adet boruyu, havşalama işlemi için verilen süre ise 45 adet boruyu içermektedir. Buna göre istasyondaki toplam standart zaman 20,4 sn'dir. Bu süre, sac malzemesi üzerinde yapılan işlem zamanıdır ve 0,34 dakikaya karşılık gelmektedir.

- Tel sarma bölümünde 2 farklı işlem gerçekleştirilmektedir. Bunlardan puntalama işlemi için verilen süre 15 adet teli içermektedir. Buna göre istasyondaki toplam standart zaman 16,8 sn'dir. $\mathrm{Bu}$ süre, tel malzemesi üzerinde yapılan işlem zamanıdır ve 0,28 dakikaya karşılık gelmektedir.

- Dolum bölümünde yapılan gözlemlerde bulunan 7 dk 26 sn'lik standart zaman 25 adet ürünü kapsamaktadır. Buna göre istasyondaki birim ürün için standart zaman 17,8 sn'dir. Bu süre, kum malzemesi üzerinde yapılan işlem zamanıdır ve 0,30 dakikaya karş1lık gelmektedir.

Bu uygulama çalışmasının amacı yukarıdaki bölümlerde de bahsedildiği üzere, kritik malzeme gruplarına (sac, kum ve tel) ait en uygun tedarikçi kombinasyonunun belirlenmesidir. Şekil 3'deki ürün ağacının sol kısmında bulunan bu malzemeler hem ürün kalitesine etkisi hem stok olarak kapladı̆̆ parasal değerin büyük olması nedeniyle kritik malzeme gruplarıdır ve çalışmanın kapsamını belirlemektedir.

Bir üründe kullanılan sac, kum ve tel miktarları 1 m'lik boru boyuna göre belirlenmektedir. Buna göre seçilen üründeki malzeme kullanım miktarları ve bunların ürün içindeki payları Tablo 3'de gösterilmiştir.

Tablo 3'de gösterilen ve $1 \mathrm{~m}$ üründeki kullanım miktarları bilinen malzemelerin seçilen üründeki kullanım miktarları, ürünün boyu olan $1,52 \mathrm{~m}$ ile çarpılarak hesaplanmıştır. Ayrıca, seçilen ürünün ağırlığı 290 g'dir. Bu ağırlık içindeki malzeme payları, malzeme ağırlığının ürün ağırlığına oranlanması yolu ile son sütunda gösterilmiştir (Örneğin, 112,5 g / $290 \mathrm{~g}=0,388$ sacın ürün içindeki payı).
Tablo 3. Bir üründe kullanılan sac, kum ve tel miktarları (Amounts of sheet, sand and wire / product)

\begin{tabular}{|c|c|c|c|}
\hline Malzeme Adı & $\begin{array}{c}\text { 1 m'deki } \\
\text { Kullanım } \\
\text { Miktarı } \\
\text { (g) }\end{array}$ & $\begin{array}{c}\text { Seçilen } \\
\text { Üründeki } \\
\text { Kullanım } \\
\text { Miktarı } \\
(\mathbf{g})\end{array}$ & $\begin{array}{c}\text { Ürün } \\
\text { İçindeki } \\
\text { Payı }\end{array}$ \\
\hline $\mathrm{Sac}$ & 74 & 112,5 & 0,388 \\
\hline $\mathrm{Kum}$ & 105 & 160 & 0,552 \\
\hline $\mathrm{Tel}$ & 5 & 7,6 & 0,026 \\
\hline
\end{tabular}

Firma bu kritik malzemeler için toplam 8 tedarikçi potansiyeline sahiptir. Tedarikçilerin malzeme bazındaki dağılımı, bu tedarikçilerin deneme üretimleri neticesinde belirlenen fire oranları ve tedarikçilere göre satın alma fiyatları Tablo 4'de gösterilmiştir.

Tablo 4. Tedarikçiler, fire oranları ve satın alma fiyatları (Suppliers, their rates of waste and purchasing prices)

\begin{tabular}{|c|c|c|c|}
\hline $\begin{array}{c}\text { Tedarikçi } \\
\text { Kodu }\end{array}$ & $\begin{array}{c}\text { Tedarik } \\
\text { Edilen } \\
\text { Malzeme }\end{array}$ & $\begin{array}{c}\text { Satın Alma } \\
\text { Fiyatı } \\
\text { (€/ton) }\end{array}$ & $\begin{array}{c}\text { Fire } \\
\text { Oranlar } \\
(\%)\end{array}$ \\
\hline T 1 & Sac & 3.200 & 1,1 \\
\hline T 2 & Sac & 2.950 & 2,8 \\
\hline T 3 & Kum & 1.300 & 1,9 \\
\hline T 4 & Kum & 950 & 4 \\
\hline T 5 & Tel & 15.000 & 0,7 \\
\hline T 6 & Tel & 13.000 & 2,1 \\
\hline T 7 & Tel & 10.000 & 3,9 \\
\hline T 8 & & & \\
\hline
\end{tabular}

\subsection{Matematiksel Model (Mathematical Model)}

$\mathrm{Bu}$ çalışmada firma amaçlarına en uygun tedarikçi kombinasyonunun ve bu tedarikçilere verilecek sipariş̧ miktarlarının belirlenmesi amacıyla, literatürde tedarikçi seçiminde sıklıkla kullanılması, birden çok hedefin varlığ 1 ve hedef değerlerinin kesin olarak bilinmesinden dolayı deterministik karışık tamsayılı hedef programlama yaklaşımı kullanılmıştır. Matematiksel modelin hazırlanmasında ilk aşamada, firmanın tedarikçiler ile ilgili hedefleri firma yöneticileri ile birlikte aşağıdaki gibi belirlenmiştir:

\section{Hedef: Fire oranlarının minimizasyonu}

2. Hedef: Kapasite kullanımının maksimizasyonu

3. Hedef: Ayrılan parasal değerin minimizasyonu.

\section{Notasyonlar}

$x_{i} i$. sac tedarikçisinden alınan malzeme miktarı

$x_{j} j$. kum tedarikçisinden alınan malzeme miktarı 
$x_{k} k$. tel tedarikçisinden alınan malzeme miktarı

$A_{i} \quad$ i. sac tedarikçisine ait ağırlıklı fire oranı

$B_{j} j$. kum tedarikçisine ait ağırlıklı fire oranı

$C_{k} k$. tel tedarikçisine ait ağırlıklı fire oranı

$b$ ağırlıklandırılmış hedeflenen fire değeri

E sacla ilgili işlemler için geçen süre

F kumla ilgili işlemler için geçen süre

$G$ telle ilgili işlemler için geçen süre

$H$ kapasitenin firın üretimi için ayrılan miktarı

$L_{i} \quad 1$ adet üründe kullanılan $i$. sacın parasal değeri

$M_{j} 1$ adet üründe kullanılan $j$. kumun parasal değeri

$N_{k} 1$ adet üründe kullanılan $k$. telin parasal değeri

$a_{1} 1$ adet üründeki sac oranı

$a_{2} \quad 1$ adet üründeki kum oranı

$a_{3} \quad 1$ adet üründeki tel oranı

$D$ talep edilen ürün miktarı

$S$ talep edilen ürün miktarındaki sac oranı

$K$ talep edilen ürün miktarındaki kum oranı

$T$ talep edilen ürün miktarındaki tel oranı

$R$ tedarikçi kombinasyonuna göre sac, kum ve tel stokları için ayrılan parasal değer

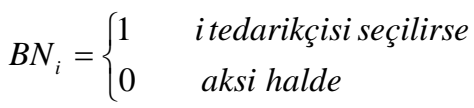

$B N_{j}= \begin{cases}1 & \text { jtedarikçisi seçilirse } \\ 0 & \text { aksihalde }\end{cases}$

$B N_{k}= \begin{cases}1 & k \text { tedarikçisi seçilirse } \\ 0 & \text { aksihalde }\end{cases}$

$n_{m} m$. negatif sapma değişkeni

$p_{m} m$. pozitif sapma değişkeni

$n_{r} \quad r$. negatif sapma değişkeni

$p_{r} \quad r$. pozitif sapma değişkeni

$n_{s} \quad s$. negatif sapma değişkeni

$p_{s} \quad s$. pozitif sapma değişkeni

$M$ büyük bir sayı

Hedef Klsitlarl

1. Hedef k1sitı:

$A_{i} x_{i}+B_{j} x_{j}+C_{k} x_{k}+n_{m}-p_{m}=b_{1} x_{i}+b_{2} x_{j}+b_{3} x_{k}$
2.Hedef kisitı:

$E x_{i}+F x_{j}+G x_{k}+n_{r}-p_{r}=H$

3. Hedef kisit1:

$L_{i} x_{i}+M_{j} x_{j}+N_{k} x_{k}+n_{s}-p_{s}=R$

Yukarıda verilen 3 hedefe ait kısıtlar öncelik sıraları değiştirilerek 18 farklı kombinasyon oluşturmaktadır. Bu 18 kombinasyon aşağıdaki temel model formülasyonunda ayrı ayrı çözülmüş ve sonuçlar Tablo 5 'de verilmiştir.

Temel Model Formülasyonu

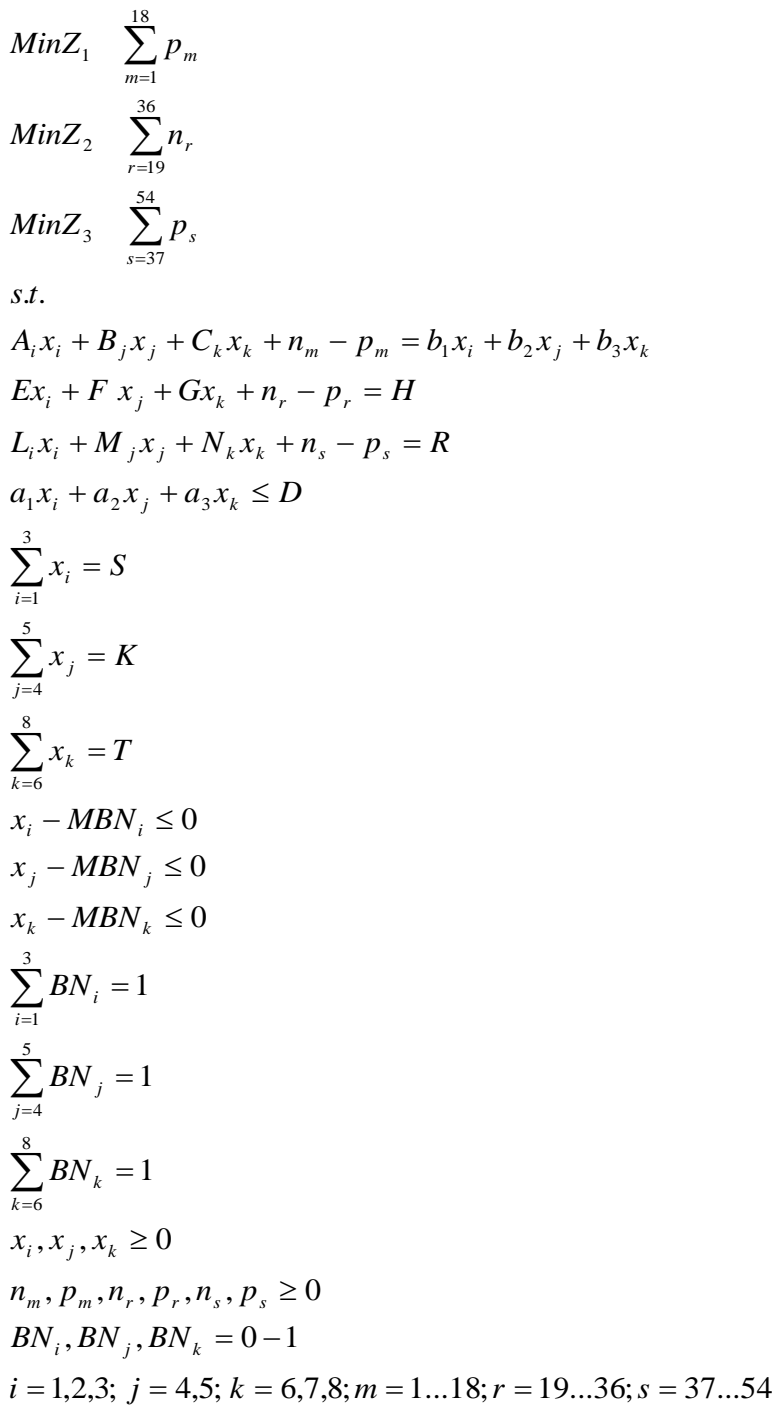

Modelin, hedef öncelikleri değiştirilerek çözümü neticesinde elde edilen tüm tedarikçi kombinasyonlarında sapma değişkenleri “0” olarak hesaplanmış ve hedeflere ulaşılmıştır. 
Tablo 5. Modelinin hedef önceliklerine göre değişen sonuçları

(Results of the model varied by the goal's priorities)

\begin{tabular}{|c|c|c|}
\hline \multicolumn{2}{|c|}{ Hedef Sirası } & Tedarikçi Kombinasyonu \\
\hline \multirow{3}{*}{$1-2-3$} & 1 & $\mathrm{~T} 1-\mathrm{T} 4-\mathrm{T} 6$ \\
\hline & 2 & T1 - T4 - T6 \\
\hline & 3 & T1 - T4 - T6 \\
\hline \multirow{3}{*}{$2-1-3$} & 1 & $\mathrm{~T} 3-\mathrm{T} 4-\mathrm{T} 8$ \\
\hline & 2 & T1 - T4 - T6 \\
\hline & 3 & $\mathrm{~T} 1-\mathrm{T} 4-\mathrm{T} 7$ \\
\hline \multirow{3}{*}{$3-1-2$} & 1 & T1 - T4 - T6 \\
\hline & 2 & T1 - T4 - T6 \\
\hline & 3 & T1 - T4 - T6 \\
\hline \multirow{3}{*}{$1-3-2$} & 1 & T1 - T4 - T6 \\
\hline & 2 & T1 - T4 - T6 \\
\hline & 3 & $\mathrm{~T} 1-\mathrm{T} 4-\mathrm{T} 7$ \\
\hline \multirow{3}{*}{$2-3-1$} & 1 & $\mathrm{~T} 3-\mathrm{T} 4-\mathrm{T} 8$ \\
\hline & 2 & $\mathrm{~T} 1-\mathrm{T} 5-\mathrm{T} 7$ \\
\hline & 3 & T1 - T4 - T6 \\
\hline \multirow{3}{*}{$3-2-1$} & 1 & $\mathrm{~T} 1-\mathrm{T} 4-\mathrm{T} 8$ \\
\hline & 2 & $\mathrm{~T} 3-\mathrm{T} 4-\mathrm{T} 8$ \\
\hline & 3 & $\mathrm{~T} 1$ - T4 - T6 \\
\hline
\end{tabular}

Firma yetkilileri, belirlenen 3 hedefin öncelik sırasını maliyet ve kâr faktörlerini temel alarak 1-2-3 ya da 3-1-2 olarak kullanmak istemişlerdir. Ancak, bu çalışmada önerilen modelin esnekliğinin gösterilmesi için 18 mümkün çözümün tamamı yukarıda sıralanmıştır. Firma yöneticilerinin talep ettiği öncelik sıralamalarının her ikisinde de Tablo 5'den de görüleceği üzere elde edilen kombinasyon T1-T4-T6'dır. Bu kapsamda, her iki öncelik sırasından elde edilen çözümlerde söz konusu tedarikçilere verilecek sipariş miktarları $\left(x_{i}, x_{j}, x_{k}\right)$ sırasılyla $772,1.098$ ve 52 ton olarak hesaplanmıştır.

\section{SONUCLAR VE ÖNERÍLER (RESULTS AND RECOMMENDATIONS)}

Günümüzde küreselleşme, sürekli gelişen teknoloji, değişen müşteri beklentileri gibi birçok faktör, firmaları mevcut sistemlerini sürekli geliştirmeleri durumunda bırakmaktadır. Bu koşullarda bulundukları sektörlerde var olabilmenin rekabet edebilme yeteneğine bağl olduğu gerçeği de düşünüldüğünde firmalar, kendilerini tedarikçilerinden müşterilerine kadar tüm unsurları yönetmek durumunda oldukları karmaşık bir yapının içinde bulmuşlardır. $\mathrm{Bu}$ gelişmelerin sonucu olarak doğan tedarik zinciri yönetiminde ilk aşamanın uygun tedarikçilerin belirlenmesi gerektiği gerçeğinden hareketle tedarikçi seçim problemi, son 10 yılda tedarik zinciri yönetimi içinde daha da büyük önem kazanmıştır [27].

$\mathrm{Bu}$ bağlamda bu çalışmada, elektrikli 1sıtıcı elemanları üreten bir firmada, fire oranlarının azaltılması, kapasite kullanım oranının artırılması ve malzeme tedariki için ayrılan ekonomik değerlerin azaltılması, başka bir ifade ile maliyetlerin minimize edilirken kaliteden ödün vermemek amacıyla kritik malzeme grupları için potansiyel tüm tedarikçiler önerilen hedef programlama modeli ile değerlendirilmiş ve firma hedeflerine en uygun tedarikçi kombinasyonu sipariş verilmesi gereken miktarlar ile birlikte bulunmuştur. Firmaya önerilen tedarikçi kombinasyonunun firmanın gerçekleştirdiği ilk satın alma işleminde kullanılması neticesinde, fire oranı fabrika genelindeki tüm üretim dikkate alındığında $\% 4,79$ 'dan \%2,46'ya düşmüştür. Bu da, \%94,8'lik bir iyileşme olduğu anlamına gelmektedir. Bunun yanı sıra, fire oranlarının fazlalığı, bakım eksiklikleri, planlama sorunları ve personel yönetimi gibi nedenlerden dolayı \%76 kapasite kullanım oranıyla çalışan firma, belirlenen tedarikçi kombinasyonu sonrasında fire oranlarında yaşanan iyileşme ile kapasite kullanım oranını \%82'ye çıkarmıştır.

Elde edilen bu iyileşmelere göre hem stokta kapladıkları alan hem bunlar için ayrılan parasal değerlerin fazlalığı hem de ürün kalite düzeyine etkisi açısından kritik malzeme olarak değerlendirilen sac, kum ve telin, firmanın ürettiği rezistansların tamamında en önemli malzemeler oluşu, uygulamanın gerçekleştirilmesi için seçilen ürünün yanı sıra firmanın tüm ürün gamı üzerinde fire oranının azaltılması ve kapasite kullanım oranının artırılması açısından tatminkar bir iyileşme sağlamıştır. Modelin çözümü neticesinde, seçilen firın rezistansı için en uygun tedarikçi kombinasyonunun yanı sıra seçilen tedarikçilere verilmesi gereken sipariş miktarlarının da elde edilmesinden hareketle, fabrikadaki tüm ürünler için bu çalışma kapsamında gerçekleştirilen standart zaman hesaplaması yapılarak daha etkin sonuçlar alınabilir. Ayrıca, ileri bir çalışma olarak birden fazla dönem için model önerisinde bulunularak literatüre katk1 sağlanabilir.

\section{KAYNAKLAR (REFERENCES)}

[1] N. Aissaoui, M. Haouari, E. Hassini, "Supplier Selection and Order Lot Sizing Modeling: A Review", Computers and Operations Research, 34(12), 3516-3540, 2007.

[2] R. Florez-Lopez, "Strategic Supplier Selection in the Add-AdValue Perspective: A CI Approach", Information Sciences, 177(5), 1169-1179, 2007.

[3] S.H. Ghodsypour, C. O'Brien, "The Total Cost of Logistics in Supplier Selection, under Conditions of Multiple Sourcing, Multiple Criteria and Capacity Constraint", International Journal of Production Economics, 73(1), 15-27, 2001. 
[4] D.Y. Sha, Z.H. Che, "Supply Chain Network Design: Partner Selection and Production/Distribution Planning Using Systematic Model", Journal of the Operational Research Society, 57(1), 52-62, 2006.

[5] T.Y. Choi, J.L. Hartley, "An Exploration of Supplier Selection Practices Across the Supply Chain", Journal of Operations Management, 14(4), 333-343, 1996.

[6] J.L. Zhang, J. Chen, "Supplier Selection and Procurement Decisions with Uncertain Demand, Fixed Selection Costs and Quantity Discounts", Computers and Operations Research, 40(11), 2703-2710, 2013.

[7] H.S. Kılıç, "An Integrated Approach for Supplier Selection in MultiItem/Multi-Supplier Environment", Applied Mathematical Modelling, 37(14-15), 7752-7763, 2013.

[8] C. Weber, J. Current, W.C. Benton, "Vendor Selection Criteria and Methods", European Journal of Operation Research, 50, 2-18, 1991.

[9] L. DeBoer, E. Labro, P. Morlacchi, "A Review of Methods Supporting Supplier Selection", European Journal of Purchasing and Supply Management. 7, 75-89, 2001.

[10] W. Ho, X. Xu, P. Dey, "Multi-Criteria Decision Making Approaches for Supplier Evaluation and Selection: A Literature Review", European Journal of Operation Research, 200, 16-24, 2010.

[11]T. Lee, T. Nhale, A. Genovese, L. Koh, "Using FAHP to Determine the Criteria for Partner's Selection within a Green Supply Chain: The Case of Hand Tool Industry in Taiwan", Journal of Manufacturing Technology Management, 23(1), 25-55, 2012.

[12] A. Genovese, S.C.L. Koh, G. Bruno, E. Esposito, "Greener Supplier Selection: State of the Art and Some Empirical Evidence", International Journal of Production Research, 51(10), 2868-2886, 2013.

[13]M. Igarashi, L. DeBoer, A. Magerholm Fet, "What Is Required for Greener Supplier Selection? A Literature Review and Conceptual Model Development", Journal of Purchasing and Supply Management, 19, 247-263, 2013.

[14] J. Chai, J.N.K. Liu, E.W.T. Ngai, "Application of Decision-Making Techniques in Supplier Selection: A Systematic Review of Literature", Expert Systems with Applications, 40, 3872-3885, 2013.

[15]A. Wetstein, E. Hartmann, W.C. Benton jr., N.O. Hohenstein, "A Systematic Assessment of Supplier Selection Literature: State of the Art and Future Scope", International Journal of Production Economics, 182, 304-323, 2016.
[16]M. Kumar, P. Vrat, R. Shankar, "A Fuzzy Programming Approach for Vendor Selection Problem in a Supply Chain", Computers and Industrial Engineering, 46, 69-85, 2004.

[17]C. Araz, P.M. Özfırat, İ. Özkarahan, "An Integrated Multicriteria Decision Making Methodology for Outsourcing Management", Computers and Operations Research, 34(12), 3738-3756, 2007.

[18]E.H. Özder, T. Eren, "Çok Ölçütlü Karar Verme Yöntemi ve Hedef Programlama Teknikleri ile Tedarikçi Seçimi”, Selçuk Üniversitesi Mühendislik, Bilim ve Teknoloji Dergisi, 4(3), 196-207, 2016.

[19]E.H. Özder, T. Eren, S. Özel Çetin, "Supplier Selection with TOPSIS and Goal Programming Methods: A Case Study", Journal of Trends in the Development of Machinery and Associated Technology, 19(1), 109-112, 2015.

[20]T.J. Kull, S. Talluri, “A Supply Risk Reduction Model Using Integrated Multicriteria Decision Making”, IEEE Transactions on Engineering Management, 55(3), 409-419, 2008.

[21]W. Tsai, S. Hung, "A Fuzzy Goal Programming Approach for Green Supply Chain Optimization under Activity-Based Costing and Performance Evaluation with a Value-Chain Structure", International Journal of Production Research, 47(18), 4991-5017, 2009.

[22]E.A. Demirtaş, O. Üstün, "Analytic Network Process and MultiPeriod Goal Programming Integration in Purchasing Decisions", Computers and Industrial Engineering, 56(2), 677-690, 2009.

[23] T. Chen, "Bivariate Models of Optimism and Pessimism in MultiCriteria Decision-Making based on Intuitionistic Fuzzy Sets", Information Sciences, 181(11), 2139-2165, 2011.

[24]A. Sadeghieh, M. Dehghanbaghi, A., Dabbaghi, S. Barak, "A Genetic Algorithm based Grey Goal Programming (G3) Approach for Parts Supplier Evaluation and Selection", International Journal of Production Research, 50(16), 4612-4630, 2012.

[25] J.P. Ignizio, Goal Programming and Extension, Lexington Books, Toronto, Canada, 126-148, 1976.

[26]R. Ramanathan, "ABC Inventory Classification with MultipleCriteria Using Weighted Linear Optimization", Computers and Operations Research, 33(3):695-700, 2006.

[27]E.C. Özcan, Tedarikçi Seçimi İçin Bir Amaç Programlama Modeli, Yüksek Lisans Tezi, Gazi Üniversitesi, Fen Bilimleri Enstitüsü, 2006. 